\title{
Psoriasis-An Immunological Disease
}

\author{
John J. Voorhees*
}

\section{Introduction}

It is a great privilege to have been selected by the Japanese Dermatological Association to present the prestigious Dohi Memorial Lecture for 1996. The individuals who have presented the Dohi Lecture have been or are the giants of our specialty. I am honored by the Japanese Dermatological Association's decision to include me among these leaders.

I am especially pleased to deliver the Dohi lecture at this time because this is the year my friend Professor Akira Ohkawara is President of the Japanese Dermatological Association. My career in psoriasis research began based on the landmark paper published in 1966 by Professors Ohkawara and Halprin (1). This paper and subsequent papers derived from it guided my research until the early 1980s.

\section{The Epidermis and Psoriasis}

In the late 1960s the epidermis of psoriasis was known to be characterized by increased proliferation (2). Researchers and clinicians alike were inspired by the striking epidermal downgrowth but were unimpressed by the comparatively sparse inflammatory infiltrate. Since the epidermal changes were so impressive, most workers considered the inflammatory cells as a secondary reaction to the epidermal pathology. Indeed, the epidermis and its accelerated growth were considered by most people to be at the heart of the disease. The assumption was that the psoriasis patient possessed genetic defects which when expressed

\footnotetext{
By invitation: Presented as the 36th Dohi Memorial International Exchange Lecture, Sapporo, Japan, June 13, 1996.

*Duncan O. \& Ella M. Poth Distinguished Professor, The University of Michigan.

Reprint requests to: John J. Voorhees, M.D., Department of Dermatology, 1910-F Taubman Center University of Michigan Medical Center, Ann Arbor, Michigan, 48109, U.S.A.
}

in the epidermis would lead to excessive epidermal cell proliferation. Thus the root cause of the disease was believed to reside mainly or entirely within the epidermis. However, the fundamental nature of this epidermal defect was a complete mystery.

A first clue came in the paper by Professor Ohkawara who working with Kenneth Halprin demonstrated that glycogen was markedly elevated in the differentiating layers of lesional epidermis (1). At about this time it was also known from the work of Earl Sutherland that glycogen could be broken down by cyclic AMP (3). Then William Bullough and colleagues demonstrated that epinephrine had the ability to inhibit epidermal cell division. Epinephrine had also been shown to raise cyclic AMP in cells (3).

Based on these observations we developed the hypothesis which stated that within psoriatic epidermis the ability to maintain normal levels of cyclic AMP might be impaired. The idea was that a low or an unstable level of cyclic AMP could account for both glycogen accumulation in the outer layers and increased proliferation in the inner layers of lesional epidermis (4). However, several years of research by our group as well as that of Halprin failed to provide data which could definitively implicate the cyclic AMP system as a key mediator of psoriatic epidermal pathology.

Although a role for cyclic AMP had not been proven, we embarked on a search for locally formed substances which could regulate cyclic AMP synthesis. This research directed our attention to the eicosanoids. Certain eicosanoids (including prostaglandin $\mathrm{E}_{2}$ ) were known to regulate cyclic AMP and to also cause vasodilation (a feature of psoriatic lesions). In 1975, we published our first paper on eicosanoids which demonstrated markedly increased levels of arachidonic acid, 12-hydroxyeicosatetraenoic acid and prostaglandin $\mathrm{E}_{2}(5)$. 
Although our work on eicosanoids began in an attempt to better understand the cyclic AMP system in epidermis, ongoing research by other workers showed that eicosanoids were major mediators of inflammation in a variety of disease settings.

A turning point came in 1983 when Knud Kragballe in Denmark discovered that benoxaprofen could markedly improve psoriasis. Benoxaprofen was a known inhibitor of 5lipoxygenase, the enzyme responsible for the formation of leukotriene $B_{4}$. As a result of his discovery, Kragballe came from Denmark to Ann Arbor and together we formulated the hypothesis that leukotriene $\mathrm{B}_{4}$ may be critical to the inflammatory and proliferative processes in psoriasis (6). This hypothesis was well received since not only did the 5-lipoxygenase inhibitor (benoxaprofen) improve psoriasis, but we had also previously detected striking increases in the substrate (arachidonic acid) of 5-lipoxygenase within lesions of psoriasis (5).

Our initial publication in 1975 (5) and the 5-lipoxygenase hypothesis (6) prompted pharmaceutical scientists to design many 5-lipoxygenase inhibitors for use in psoriasis. Since the mid-80s we and others have performed clinical trials on over one dozen such inhibitors without a single convincing result. It appears that the drugs do not enter the skin, or benoxaprofen has other activities which caused psoriasis to clear, or the leukotriene pathway is too far downstream for drug blockade to make a clinical difference.

\section{Immunology and Psoriasis}

Although inflammation (especially polymorphonuclear leukocytes) had been discussed in the context of psoriasis, it was not until the 1979 report of Mueller and Herrmann, whose serendipitous discovery that cyclosporine could clear psoriasis, that immunology began to be considered in psoriasis (7). At that time cyclosporine was primarily used to prevent transplant rejection and was little used for other immunological diseases. For this reason and its unfamiliarity to us we did not seriously consider an immunologic basis for psoriasis at that time. Rather, we were drawn to cyclosporine in the

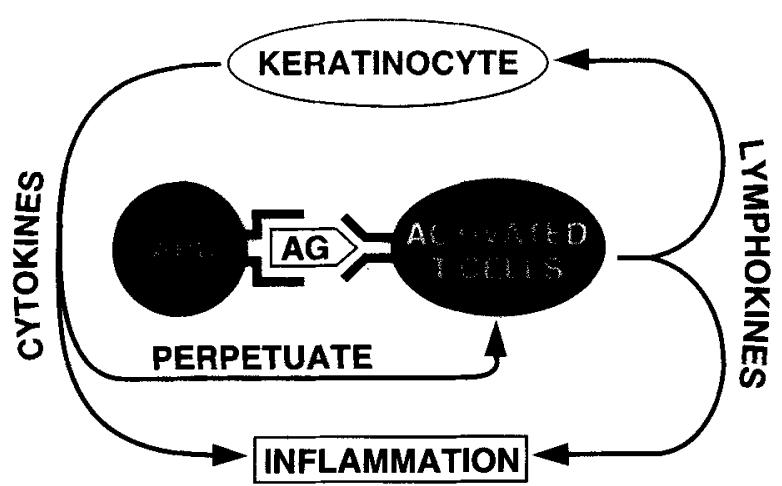

Fig. 1. Overview of the activated skin immune system in psoriasis. See text for explanation.

early $80 \mathrm{~s}$ because it had been reported to inhibit the formation of leukotriene $\mathrm{B}_{4}(8)$. In the early 80 s we still believed that leukotriene $B_{4}$ was important because the many negative leukotriene $\mathrm{B}_{4}$ inhibitor clinical trials had not yet been performed. Therefore, cyclosporine's ability to inhibit leukotriene $B_{4}$ was the rationale for our first trial of cyclosporine in psoriasis. The results of this trial, the first double-blind trial of cyclosporine in psoriasis in the world, confirmed the open study of Mueller and Herrmann. Our double-blind study was published in late $1986(8)$. However, also in late 1986, Griffiths and Fry, working independently in England, published an open study which taken together with our doubleblind study provided definitive proof of cyclosporine's efficacy in psoriasis $(8,9)$.

Although we had undertaken the cyclosporine trial because it was said to inhibit leukotriene $\mathrm{B}_{4}$, literature was rapidly appearing which indicated that the primary action of cyclosporine was to inhibit lymphokine release and proliferation of $T$ cells. At around this time Dr. Kevin Cooper, who had been trained by Steve Katz, was appointed Assistant Professor at our Department of Dermatology. This was the beginning of a 10-year collaboration between Cooper and myself during which time we, as well as many other researchers, established that in psoriasis the immune system plays an important role. Today it is widely accepted that although the cause of the disease is unknown, the $T$ cell is a critical mediator of the clinical expression of the disease. For this reason, in 
the remainder of this lecture I will provide an overview of our current understanding of the immunological basis of psoriasis. Although cyclic AMP and leukotrienes may play a role in lesional molecular pathology, the immunological aspects of psoriasis are so compelling that we no longer investigate these latter two areas.

\section{The Skin Immune System in Psoriasis}

Psoriatic epidermis is characterized by not only increased cell proliferation but also keratinocyte activation. Activated keratinocytes release cytokines of several types which cause inflammation and perpetuation of a classical cell-mediated immune response. Within lesions the immune response is characterized by an interaction between antigen-presenting cells (APC) and T cells (10). As shown in Figure 1 this interaction occurs as an antigen is being presented to lesional T cells by lesional APCs. The APCs have on their surface either major histocompatibility class (MHC) I or class II molecules. The antigen to be presented to the $T$ cell is lodged in either the MHC class I or II binding pocket on the APC.

In psoriasis the identity of this antigen has yet to be found. However, whatever the identity of the psoriasis antigen(s), it is likely to be a protein. Such proteins are chopped into small peptides by the APC and it is these peptides that then fit into MHC class I or II for presentation to $\mathrm{T}$ cells. Although the psoriasis antigen(s) has yet to be identified, it is likely that one such peptide will be derived from a streptococcal antigen. It is commonly known that a sizable fraction of patients with acute guttate psoriasis have as a precipitating factor, an antecedent streptococcal infection (11). However many patients, especially those with plaque psoriasis, have no detectable streptococcal infection. For this reason, it may be that several different foreign or auto-antigens may trigger the APC-T cell interaction in patients with suitable genetic susceptibility.

\section{Antigen Presenting Cells in Psoriasis}

In normal human skin APCs are represented by MHC II (HLA-DR ${ }^{+}$) positive Langerhans cells. We therefore sought to identify those
APCs contained within psoriatic lesions. We demonstrated that $\mathrm{CD} 1 \mathrm{a}^{+} \mathrm{DR}^{+}$Langerhans cells are present in similar numbers in lesional and non-lesional skin and therefore were unlikely to be the pathogenic APCs in lesions. However, when $\mathrm{CDla} \mathrm{DR}^{+}$cells were removed from lesional cell suspensions, the APC activity was markedly reduced. Thus the APC activity driving $T$ cells within lesions is composed of non-Langerhans cell $\mathrm{CD}^{-} \mathrm{a}^{-} \mathrm{DR}^{+}$macrophagelike cells (12).

However, more recently it has been shown that a second type of APC is present within lesional dermis. This APC has been termed the dermal dendrocyte, is located in the high papillary dermis around blood vessels, and is factor-XIIIA positive. These APCs are also activated and, thus, it appears that in psoriatic lesions at least two types of APCs are responsible for the heightened APC activity found in lesions. This leads to the hypothesis that lesional APCs promote lesional T cell activation by presenting the $T$ cell with either a foreign or a self antigen.

A corollary of this hypothesis is that psoriasis genes encode susceptibility to skin autoimmunity. Activated T cells in this scenario would release lymphokines which directly or indirectly induce keratinocyte proliferation and altered epidermal differentiation. In this context a major pathophysiological pathway in psoriasis is autoimmune wounding of the epidermis. Thus, psoriasis may be considered as another example of a $T$ cell mediated autoimmune disease. In fact the only missing link appears to be the identity of the antigens which in the proper genetic context can trigger $\mathrm{T}$ cell activation. Thus, the thinking in psoriasis research has undergone a major shift away from one of epidermal causation to one of an epidermal response (i.e. chronic proliferation and disordered differentiation) to immunologic injury.

\section{T Cells in Psoriasis}

In psoriatic lesions both $\mathrm{CD} 4^{+}$and $\mathrm{CD} 8^{+} \mathrm{T}$ cells have been described (reviewed in ref 10). Furthermore, although both types of $\mathrm{T}$ cells have been found in epidermis and dermis of 


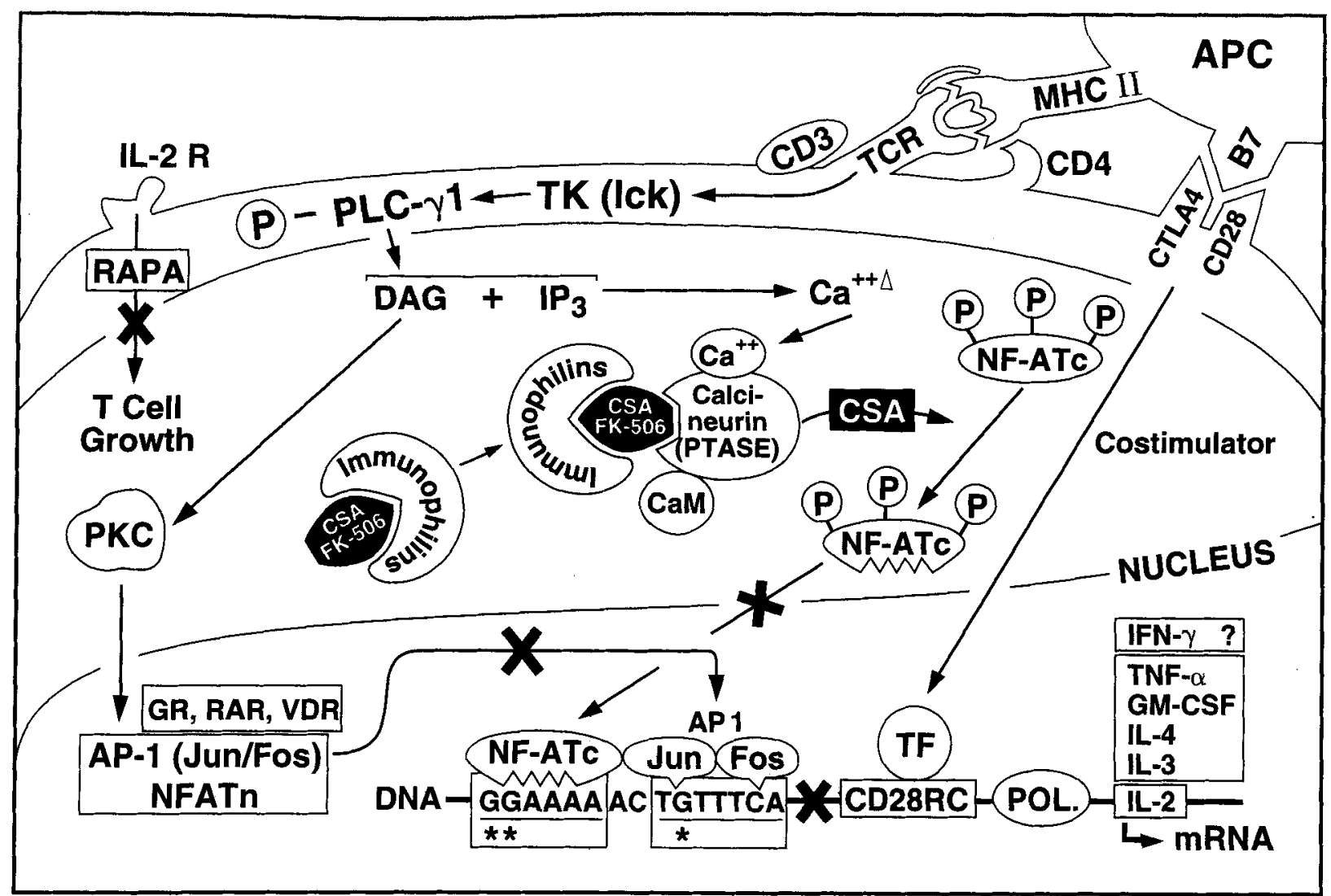

Fig. 2. Regulation of cytokine gene transcription in activated T cells. An X marks the site of inhibition that characterizes anti-psoriasis drugs. RAPA-rapamycin; GR, RAR and VDR-glucocorticoid, retinoid, and vitamin $\mathrm{D}_{3}$ receptors, respectively; $\mathrm{CSA}-$-cyclosporine. A detailed description of this diagram can be found in the text.

lesions, a majority of $\mathrm{T}$ cells in the dermis are $\mathrm{CD}^{+}$and in the epidermis are $\mathrm{CD}^{+}(13)$. Psoriasis has a strong association with both HLA-Cw6 and DR7. The interest in HLA associations stems from the fact that inherited differences in HLA (MHC) proteins could account for why one person with a certain HLA phenotype manifests psoriasis and another person who inherited a different protein phenotype does not. In other words one type of inherited HLA phenotype would present an antigen to a $T$ cell while another phenotype could not do so. It is interesting to note that $\mathrm{CD}^{+} \mathrm{T}$ cells interact with APCs carrying MHC class II (eg. HLA-DR7 $7^{+}$) and $\mathrm{CD}^{+} \mathrm{T}$ cells interact with APCs which express MHC class I (eg. HLA-Cw $6^{+}$). Thus the presence of both $\mathrm{CD}^{+}$and $\mathrm{CD}^{+} \mathrm{T}$ cells in lesions is in accord with the strong association of psoriasis with both class I and II MHC molecules.

In lesions the presentation of an antigenic peptide by an MHC molecule on the surface of an APC to the T cell receptor on the surface of a $T$ cell can be considered by analogy to a hormone and its receptor. In this comparison the antigenic peptide is the hormone and the $T$ cell receptor on the $T$ cell is the hormone receptor. Like a hormone binding to its cognate receptor, the antigen upon binding to its $T$ cell receptor stimulates a signal transduction cascade within the $T$ cell. As shown in Figure 2, this signalling utilizes protein kinase $\mathrm{C}$, calcineurin phosphatase, costimulatory signals CD28 and CTLA-4, activating protein 1 (AP-1), and nuclear factor of activated $T$ cells (NFAT). Thus, recognition of an antigen by its receptor on the surface of a $\mathrm{T}$ cell causes a molecular cascade to occur which terminates on enhancer 
elements within the promoters of cytokine genes in $T$ cells. This results in the production of IL-2 for T cell proliferation and the production of interferon $\gamma($ IFN $\gamma$ ) and IL-4 for various kinds of $\mathrm{T}$ cell mediated responses.

Abundant evidence exists to substantiate the presence of activated (and therefore potentially disease causing) $T$ cells within lesions. The ultimate manifestation of $\mathrm{T}$ cell activation is $\mathrm{T}$ cell proliferation. Using a marker for cell proliferation we reported that $37 \%$ of all proliferating cells within the dermis of lesions were $\mathrm{CD} 45 \mathrm{RO}+$ memory $\mathrm{T}$ cells (14). In addition other well accepted markers of $\mathrm{T}$ cell activation are present on lesional $T$ cells such as HLA-DR and IL-2 receptor positivity.

Activated T cells in general produce one of two types of lymphokines (cytokines derived from $\mathrm{T}$ cells). T-1 lymphokines are IL-2 and IFN $\gamma$ which mediate cellular immunity and T-2 lymphokines are IL-4, 5 and 10 which mediate humoral immunity. $T$ cells within lesions have been shown to produce the T-1 lymphokines, IL-2 and IFN $\gamma$ (15-17). The injection of IL-2 or IFN $\gamma$ into psoriasis patients has resulted in disease flares in significant numbers of patients (reviewed in ref 10 ). In addition, lymphokinecontaining supernatants, prepared from $\mathrm{T}$ cells cloned from psoriatic lesions, caused the proliferation of uninvolved psoriatic keratinocytes when the supernatants were added to the keratinocytes in vitro. If neutralizing antibodies to IFN $\gamma$ were added to the supernatants prior to addition to keratinocyte cultures, keratinocyte growth was inhibited (18). These data indicate that IFN $\gamma$ released from $\mathrm{T}-1$ type $\mathrm{T}$ cells within lesions is likely to be a critical factor in disease pathogenesis.

\section{Immunotherapy of Psoriasis}

So it is, that based on the above discussion, the treatment of psoriasis has been sharply focused on the lesional immune system and away from the epidermis as an organ responding to immune injury. The immunological unit, the APC-antigen-T cell, which is found in the psoriatic lesion is called by immunologists the ternary complex. This complex is a hallmark of a $\mathrm{T}$ cell mediated disease. Activation of this
Table 1. Ternary complex therapy of psoriasis

\begin{tabular}{|c|c|}
\hline $\begin{array}{l}\text { - MTX (Adenosine- } A_{2} \text { ) } \\
\text { - 2-Chlorodeoxyadenosine } \\
\text { - Sulfasalazine }\end{array}$ & $\begin{array}{l}\text { - Steroid } \\
\text { - Retinoid } \\
\text { - Vitamin } D_{3}\end{array}$ \\
\hline $\begin{array}{l}\text { - UVB } \\
\text { - PUVA }\end{array}$ & \multirow{2}{*}{$\begin{array}{l}\text { - Anti CD3 } \\
\text { - Anti CD4 } \\
\text { - CTLA-4 Ig }\end{array}$} \\
\hline - T-Cell Death (IL-2-Toxins) & \\
\hline - CSA & - Peptide Vaccine \\
\hline $\begin{array}{l}\text { - FK506 } \\
\text { - Ascomycin } \\
\text { - Rapamycin }\end{array}$ & $\begin{array}{l}\text { - IL-10 } \\
\text { - Anti-IL-12 } \\
\text { - Anti-IFN } y\end{array}$ \\
\hline
\end{tabular}

complex is believed to be sufficient to cause clinical disease. Autoimmune diseases other than psoriasis believed to be caused by different ternary complexes are multiple sclerosis, insulin-dependent diabetes, inflammatory bowel disease, and rheumatoid arthritis (19).

Since the entire intact ternary complex is necessary for immune mediation, it follows that impairment of any part of the complex should be sufficient to improve disease. The table lists many drugs which have been used or are experimentally being used to treat psoriasis. Although many agents listed in the Table 1 may have multiple pharmacologic effects, they all have one mechanism in common, immunosuppression. Methotrexate promotes the accumulation of extracellular adenosine which via A2 receptors causes immunosuppression (20). Sulfasalazine appears to act via a similar mechanism of adenosine accumulation $(20,21)$. UV irradiation appears to cause immunosuppression by inducing the formation of IL-10 $(22,23)$ which is believed to be a natural suppressant of the cutaneous inflammatory response (24). Thus a well controlled trial of IL-10 in psoriasis would appear to be in order.

Cyclosporine, FK506, ascomycin and rapamycin all impair the signal transduction mechanism within $T$ cells and thereby block $T$ cell growth and cytokine (eg. IFN $\gamma$ ) release (see Figure 2 which has the site of action of these drugs indicated). Although steroids, retinoids and vitamin $\mathrm{D}$ have multiple actions, they too block $\mathrm{T}$ cell signalling at the level of $\mathrm{NF} \kappa \mathrm{B}$ and NFAT/AP-1 thereby impairing the transcrip- 
tion of lymphokine genes in $\mathrm{T}$ cells $(25,26)$. Anti- $\mathrm{CD}_{3}$ and anti-CD $\mathrm{C}_{4}$ also block $\mathrm{T}$ cell signalling but in contradistinction to the above agents, the antibodies bind to their cognate $T$ cell surface proteins and impair $T$ cell activation from its initiation at the $\mathrm{T}$ cell surface (reviewed in 10). In addition to activation of the $\mathrm{T}$ cell receptor by antigen, a productive $\mathrm{T}$ cell activation also requires a second signal called the B-7/CD28 pathway. A molecule known as CTLA-4Ig binds to B-7 and prevents it from interacting with CD28 to provide the 2 nd signal (27). This causes immunosuppression by inducing $T$ cell antigen desensitization, anergy or apoptosis. CTLA-4Ig is currently being tested for possible utility in psoriasis.

\section{Perspectives}

Thus in the 30 years since Professor Ohkawara and I have been investigating psoriasis, a major paradigm shift has occurred, largely due to the advent of cyclosporine. In the early years psoriasis was thought to be an epidermal disease. Now we know that psoriasis is driven by the activated cellular immune mechanism discussed above. Now and in the future, new therapies will be studied for their ability to impair the local lesional hyperactive immune response. Although the immune response is appreciated to be the critical driver of disease expression, the cause of psoriasis remains unknown. In an attempt to address the cause of this disease we have undertaken a molecular genetic analysis of psoriasis. It is our hope that this approach will lead to identification of those genes which cause this disease.

\section{References}

1) Halprin KM, Ohkawara A: Carbohydrate metabolism in psoriasis: An enzymatic study, J Invest Dermatol, 46: 51-69, 1966.

2) Weinstein DG, Frost P: Abnormal cell proliferation in psoriasis, J Invest Dermatol, 50: 254, 1968.

3) Robinson GA, Butcher RW, Sutherland EW: Cyclic AMP, Academic Press, New York, 1971.

4) Voorhees JJ, Duell EA: Psoriasis as a possible defect of the adenyl cyclase-cyclic AMP cascade, Arch Dermatol, 104: 352-358, 1971.

5) Hammarstrom $S$, Hamberg M, Samuelsson B, Duell EA, Stawiski M, Voorhees JJ: Increased concentra- tions of nonesterified arachidonic acid, 12L-hydroxy5,8,10,14-eicosatetraenoic acid, prostaglandin $\mathrm{E}_{2}$, and prostaglandin F2 $\alpha$ in epidermis of psoriasis, Proceedings of the National Academy of Sciences, 72: 5130-5134, 1975.

6) Voorhees IJ: Leukotrienes and other lipoxygenase products in the pathogenesis and therapy of psoriasis and other dermatoses, Arch Dermatol, 119: 541-547, 1983.

7) Mueller W, Herrmann B: Cyclosporin A for psoriasis, N EnglJ Med, 301: 555, 1979.

8) Ellis CN, Gorsulowsky DC, Hamilton TA, et al: Cyclosporine A improves psoriasis in a double-blind study, $J$ American Med Assoc, 256: 3110-3116, 1986.

9). Griffiths CEM, Powles AV, Leonard JN, Fry L, Baker BS, Valdimarsson $\mathrm{H}$ : Clearance of psoriasis with low dose cyclosporin, Brit Med J, 293: 731-732, 1986.

10) Griffiths CEM, Voorhees IJ: Immunological mechanisms involved in psoriasis, Springer Semin Immunopathol, 13: 441-454, 1992.

11) Valdimarsson H, Baker BS, Jonsdottir I, Powles A, Fry L: Psoriasis: A T-cell-mediated autoimmune disease induced by streptococcal superantigens?, Immunol Today, 16: 145-149, 1995.

12) Baadsgaard O, Gupta AK, Taylor RS, Ellis CN, Voorhees JJ, Cooper KD: Psoriatic epidermal cells demonstrate increased numbers and function of non-Langerhans antigen-presenting cells, $J$ Invest Dermatol, 92: 190-195, 1989.

13) Menssen A, Trommler P, Vollmer S, et al: Evidence for an antigen-specific cellular immune response in skin legions of patients with psoriasis vulgaris, $J$ Immunology, 155: 4078-4083, 1995.

14) Morganroth GS, Chan LS, Weinstein GD, Voorhees JJ, Cooper KD: Proliferating cells in psoriatic dermis are comprised primarily of T cells, endothelial cells, and factor XIIIa ${ }^{+}$perivascular dendritic cells, $J$ Invest Dermatol, 96: 333-340, 1991.

15) Uyemura K, Yamamura M, Fivenson DF, Modlin RL, Nickoloff BJ: The cytokine network in lesional and lesion-free psoriatic skin is characterized by a $\mathrm{T}$ helper type 1 cell-mediated response, I Invest Dermatol, 101: 701-705, 1993.

16) Schlaak JF, Buslau M, Jochum W, et al: $T$ cells involved in psoriasis vulgaris belong to the Th1 subset, J Invest Dermatol, 102: 145-149, 1994.

17) Nestle FO, Turka LA, Nickoloff BJ: Characterization of dermal dendritic cells in psoriasis: Autostimulation of T lymphocytes and induction of Th1 type cytokines, J Clin Invest, 94: 202-209, 1994.

18) Bata-Csorgo Z, Hammerberg C, Voorhees JJ, Cooper $\mathrm{KD}$ : Intralesional T-Iymphocyte activation as a mediator of psoriatic epidermal hyperplasia, $J$ Invest Dermatol, 105: 89s-94s, 1995.

19) Bach J-F: Organ-specific autoimmunity, Immunol Today, 16: 353-355, 1995.

20) Cronstein BN: A novel approach to the development 
of anti-inflammatory agents: Adenosine release at inflamed sites, $J$ Investigative Medicine, 43: 50-57, 1995.

21) Gandangi $P$, Longaker $M$, Naime $D$, et al: The antiinflammatory mechanism of sulfasalazine is related to adenosine release at inflamed sites, J Immunol, 156: 1937-1941, 1996.

22) Rivas JM, Ullrich SE: The role of IL-4, IL-10, and TNF- $\alpha$ in the immune suppression induced by ultraviolet radiation, J Leukocyte Biology, 56: 769-775, 1994.

23) Enk CD, Sredni D, Blauvelt A, Katz SI: Induction of IL-10 gene expression in human keratinocytes by UVB exposure in vivo and in vitro, J Immunol, 154: 4851-4856, 1995.

24) Berg DJ, Leach MW, Kuhn R, et al: Interleukin 10 but not interleukin 4 is a natural suppressant of cuta- · neous inflammatory responses, $J$ Exp Med, 182: 99-108, 1995.

25) Scheinman RI, Cogswell PC, Lofquist AK, Baldwin Jr AS: Role of transcriptional activation of $\mathrm{I} \kappa \mathrm{B} \alpha$ in mediation of immunosuppression by glucocorticoids, Science, 270: 283-286, 1995.

26) Alroy I, Towers TL, Freedman LP: Transcriptional repression of the interleukin-2 gene by vitamin $D_{3}$ : Direct inhibition of NFATp/AP-1 complex formation by a nuclear hormone receptor, Molec and Cell Biology, 15: 5789-5799, 1995.

27) Judge TA, Tang A, Spain LM, Gratiot-Deans J, Sayegh MH, Turka LA: The in vivo mechanism of action of CTLA4Ig' J Immunol, 156: 2294-2299, 1996. 